\title{
Penyegaran Kader Kesehatan Jiwa Mengenai Deteksi Dini Gangguan Jiwa dan Cara Merawat Penderita Gangguan Jiwa
}

\author{
Ira Kusumawaty ${ }^{1}$, Yunike ${ }^{2 *}$, Marta Pastari $^{3}$ \\ ${ }^{1,2,3}$ Poltekkes Palembang, Indonesia \\ caby_deh@yahoo.com
}

\begin{abstract}
ABSTRAK
Kader kesehatan jiwa memiliki keterjangkauan terdekat dengan masyarakat dalam membantu meningkatkan kesehatan jiwanya. Namun demikian, fakta memperlihatkan masih minimnya pemahaman kader kesehatan jiwa mengenai deteksi dini gangguan jiwa serta cara merawat penderita gangguan jiwa.Tujuan kegiatan ini adalah untuk meningkatkan pemahaman dan kemampuannya dalam mendeteksi dini gangguan jiwa serta merawat penderita gangguan jiwa. Metode yang digunakan adalah ceramah, diskusi, tanya jawab dan demonstrasi disertai penggunaan video, slide serta leaflet sebagai media penyegaran. Hasil kegiatan penyegaran memperlihatkan adanya peningkatan prosentase pemahaman kader dari 40\% menjadi $75 \%$ dalam menjelaskan mengenai kesehatan jiwa, tanda dan gejala gangguan jiwa yang sering muncul. Peningkatan prosentase kemampuan kader tentang cara merawat penderita gangguan jiwa juga meningkat dari $25 \%$ menjadi $80 \%$, yang diperlihatkan melalui demonstrasi. Kegiatan penyegaran kader dapat meningkatkan pemahaman tentang deteksi dini gangguan jiwa dan cara merawat penderita gangguan jiwa, sehingga diharapkan pemahamannya tersebut dapat meningkatkan kepeduliannya dalam membantu meningkatkan kesehatan jiwa masyarakat.
\end{abstract}

Kata Kunci: Deteksi Dini, Gangguan Jiwa, Kader Kesehatan Jiwa, Merawat, Penyegaran

\section{PENDAHULUAN}

Urgensi peran kader kesehatan jiwa bagi masyarakat tidak dapat diragukan lagi. Kedekatannya dengan masyarakat menjadikan kader kesehatan jiwa sebagai ujung tombak keberhasilan dalam mengatasi permasalahan kesehatan jiwa ataupun mempromosikan kesehatan jiwa. Keberadaan kader di posyandu menuntut kader kesehatan untuk menyediakan waktu dan mengekspresikan kepeduliannya kepada masyarakat sekitar. Sikap empati menjadikan kader kesehatan jiwa dapat lebih produktif dalam memberikan bantuan. Namun demikian, fakta memperlihatkan bahwa banyak posyandu kesehatan jiwa yang belum memberikan pelayanannya secara aktif. Bahkan berdasarkan survey awal di puskesmas yang telah memiliki posyandu jiwa, diketahui bahwa empat dari lima kader kesehatan jiwa mengungkapkan ketidaktahuannya dalam merawat atau mengenal tanda awal terjadinya gangguan jiwa. Padahal jika gejala 
gangguan jiwa dapat dideteksi lebih dini, maka kemungkinan untuk terpuruk pada kondisi yang lebih parah dapat dicegah secepat mungkin (Bebbington, 2001), sehingga dapat meringankan beban keluarga (Chadda, Singh, \& Ganguly, 2007; Chan, 2011).

Sebagaimana data yang disampaikan oleh Badan Kesehatan Dunia atau World Health Organization (2014), terjadi peningkatan gangguan jiwa yang cukup signifikan, terutama depresi, padahal depresi memberikan implikasi yang sangat buruk bukan hanya bagi penderita, namun juga keluarganya. Hasil riset kesehatan dasar juga menunjukkan data yang sama, yaitu terjadinya peningkatan kasus yang tidak dapat dianggap sederhana (Kementerian Kesehatan, 2019).

Kepatuhan minum obat juga menjadi penghambat keberhasilan pemulihan penderita. Kepatuhan penderita dalam meminum obat, masih menjadi masalah besar, bahwa tidak sampai $50 \%$ penderita yang patuh dalam meminum obatnya. Salah satu kondisi tersebut terjadi di Sumatera Selatan dengan prosentase kepatuhan minum obat masih di bawah level nasional, yaitu hanya $35,4 \%$ sedangkan prosentase level nasional adalah $48,9 \%$ (Kementerian Kesehatan, 2019) Kondisi tersebut dapat diminimalisir jika kader kesehatan jiwa berkontribusi lebih besar di tengah-tengah masyarakat. Beranjak dari kondisi tersebut, maka dilaksanakan kegiatan pengabdian kepada masyarakat berupa penyegaran kepada kader kesehatan jiwa mengenai kesehatan jiwa, dengan harapan kader dapat melakukan deteksi dini gangguan jiwa serta mampu merawat penderita gangguan jiwa.

\section{METODE}

Pelaksanaan penyegaran telah dilaksanakan pada tanggal 25 Oktober 2019 bertempat di ruang pertemuan Puskesmas 1 Ulu Palembang. Kegiatan berlangsung selama 2 jam 30 menit, dari pukul 09.30-12.00 WIB. Acara penyegaran dibuka oleh kepala puskesmas dan dilanjutkan dengan pelaksanaan penyegaran. Dalam pelaksanaan penyegaran, media audiovisual yang digunakan dalam kegiatan ini berupa video, slide dan media cetak yaitu leaflet. Pelaksanaan penyegaran secara umum dilaksanakan melalui penyuluhan, yang bertujuan untuk meningkatkan pengetahuan dan kemampuan kader kesehatan jiwa dalam mendeteksi gangguan jiwa serta merawat penderita gangguan jiwa. Metoda yang digunakan adalah: ceramah, tanya jwab, diskusi serta demonstrasi.

Pada tahap awal, pelaksana mengajukan pertanyaan tentang gangguan jiwa serta cara merawat penderita gangguan jiwa secara tertulis kepada para kader. Dilanjutkan dengan penyampaian materi yang diselingi dengan proses tanya jawab dan diskusi. Pada saat sesi diskusi, para kader memberikan masukan agar pelaksanaan pemberian pelayanan posyandu jiwa dapat lebih efektif. Metode demonstrasi juga diterapkan dalam kegiatan penyegaran ini dimaksudkan agar kader tidak hanya memahami konsep atau teori saja, mereka harus mampu merawat penderita gangguan jiwa. Setelah pelaksanaan demonstrasi, para kader diminta untuk menjawab pertanyaan yang diajukan serta mendemonstrasikan kembali cara merawat penderita gangguan jiwa. Penyajian secara deskriptif dilaksanakan berdasarkan hasil analisis kegiatan penyegaran melalui penyuluhan dan demonstrasi.

\section{HASIL}

Berdasarkan proses penyegaran yang telah dilaksanakan, dapat dikemukakan hasilnya sebagai berikut bahwa terjadi peningkatan pengetahuan tentang deteksi dini gangguan jiwa pada seluruh kader. Sebelum pelaksanaan penyegaran, secara rata-rata $40 \%$ pertanyaan dapat dijawab dengan baik oleh seluruh kader dan peningkatan 
prosentase kemampuan menjawab pertanyaan meningkat menjadi $75 \%$ setelah pelaksanaan penyegaran. Adapun kemampuan merawat penderita gangguan jiwa, juga memperlihatkan adanya peningkatan kemampuan kader, yang semula kemampuannya hanya $25 \%$, namun setelah penyegaran kemampuan mereka meningkat menjadi $80 \%$.

\section{PEMBAHASAN}

Gangguan jiwa merupakan masalah yang tidak hanya membebani secara psikologis, namun juga secara finansial dan sosial. Belum lagi stigma yang sulit dilepaskan pada sosok seorang penderita gangguan jiwa maupun keluarganya (Grover et al., 2017; Lauber \& Rössler, 2007; Lv, Wolf, \& Wang, 2013). Kepedulian kader kesehatan jiwa amat besar, karena penderita dan keluarganya membutuhkan bimbingan, perhatian serta memperoleh kesempatan untuk mengaktualisasikan potensinya di masyarakat.

Peningkatan pengetahuan menunjukkan antusiasme kader untuk memahami dan secara tidak langsung menggambarkan keinginannya untuk membantu penderita dan keluarganya. Peningkatan kemampuan dalam merawat penderita, yang diperlihatkan kader melalui demonstrasi cara merawat saat pelaksanaan penyegaran mengindikasikan itikad baik untuk menolong serta membantu dengan sepenuh hati.

Penggunaan media saat pelaksanaan penyegaran turut menentukan keberhasilan pencapaian target penyegaran. Sebagaimana kegiatan pengabdian kepada masyarakat sebelumnya, bahwa salah satu penentu keberhasilan menyampaikan informasi adalah jenis media yang digunakan dan media audiovisual ditengarai memberikan dampak positif dibandingkan media lainnya (Simamora \& Saragih, 2019). Dukungan maksimal dari pimpinan puskesmas serta pengelola, menjadi faktor eksternal yang tidak dapat dikesampingkan, karena menjadi motor pendorong terlaksananya pelayanan pada posyandu kesehatan jiwa.

\section{KESIMPULAN}

Optimalisasi pelayanan posyandu kesehatan jiwa dapat terwujud jika kader kesehatan telah memahami topik kesehatan jiwa secara seutuhnya. Pemahaman tentang kesehatan jiwa, gangguan jiwa dapat membekali kader kesehatan jiwa dalam mendeteksi secara dini gangguan jiwa di lingkungan masyarakat. Membekali kemampuan dalam merawat penderita gangguan jiwa, menjadi faktor yang tidak kalah pentingnya dalam mengotimalkan kiprah kader kesehatan jiwa dalam memberikan pelayanan kepada masyarakat.

\section{REFERENSI}

Bebbington, P. (2001). The World Health Report 2001. Social Psychiatry and Psychiatric Epidemiology, 36(10), 473-474. https://doi.org/10.1007/s001270170010

Chadda, R. K., Singh, T. B., \& Ganguly, K. K. (2007). Caregiver burden and coping. Social Psychiatry and Psychiatric Epidemiology, 42(11), 923-930. https://doi.org/10.1007/s00127-007-0242-8

Chan, S. W. chi. (2011). Global Perspective of Burden of Family Caregivers for Persons With Schizophrenia. Archives of Psychiatric Nursing, 25(5), 339-349. https://doi.org/10.1016/j.apnu.2011.03.008 
Grover, S., Avasthi, A., Singh, A., Dan, A., Neogi, R., Kaur, D., Behere, P. (2017). Stigma experienced by caregivers of patients with severe mental disorders: A nationwide multicentric study. International Journal of Social Psychiatry, 63(5), 407-417. https://doi.org/10.1177/0020764017709484

Kementerian Kesehatan (2019). Riset Kesehatan Dasar.

Lauber, C., \& Rössler, W. (2007). Stigma towards people with mental illness in developing countries in Asia. International Review of Psychiatry, 19(2), 157-178. https://doi.org/10.1080/09540260701278903

Lv, Y., Wolf, A., \& Wang, X. (2013). Experienced stigma and self-stigma in Chinese patients with schizophrenia. General Hospital Psychiatry, 35(1), 83-88. https://doi.org/10.1016/j.genhosppsych.2012.07.007

Simamora, R. H., \& Saragih, E. (2019). Penyuluhan kesehatan masyarakat : Penatalaksanaan perawatan penderita asam urat menggunakan media audiovisual Public health counseling: Management of care for gout patients using audiovisual media, Jurnal Pendidikan dan Pemberdayaan Masyarakat, 6(1), 24-31.

World Health Organization. (2014). Fact sheet: Mental health and wellbeing. Geneva. 